\section{EL GOTERO}

Miguel Signes Molinés

A mi querido y eminente cardiólogo,

Dr. D. Jomás Richant Sotés

Con todo agradecimiento

Los que me vieron a mi llegada al sanatorio dijeron que yo tenía un feo color ceniza y la frente perlada de gotas de sudor frío. No me vi la cara en aquellos momentos. Tampoco se me ocurrió pasarme la mano por la frente. No sé si hubiera podido. Las escasas fuerzas que me quedaban, los últimos alientos los precisaba para concentrar la mente en el horrible dolor que sentía en mitad del pecho, a lo largo del lado izquierdo del esternón.

No podré nunca describir la hondura y extrañeza de aquel dolor, sin semejanza posible a cualquier otro que pueda experimentar la criatura humana. No creo que haya palabras para describirlo. Tenía yo la impresión de tener clavada, hasta muy adentro, en medio de la tabla del pecho, la gruesa cuña del hacha del leñador vascongado. Si de alguna manera puede hablarse del dolor que yo sentía es diciendo que, aquél, era un dolor de muerte, un dolor contra el que era inútil defenderse, un dolor que te dejaba empequeñecido, acobardado, angustiadamente solo, como está siempre el que muere. Un dolor que ni siquiera te permite tomar conciencia -como en mi caso- de la presente y transida realidad de la esposa tan pálida como tú, tan brutalmente sumergida en el radical temor, en la radical desorientación que poduce la vivencia de la catástrofe esperada e inminente...

Sin darme apenas cuenta, sin que aquel movimiento de médicos, practicantes y enfermeras en torno a mi cama tuviese para mí un sentido demasiado preciso, pues sólo le quedaba a mi conciencia capacidad para albergar el dolor que pugnaba por matarme, me vi, casi de repente, después de ciertas manipulaciones que hicieron conmigo, en presencia de un extraño personaje, alto, envarado, brillante, que se comunicaba conmigo, íntimamente, a través de un delgado conducto de goma hialina y traslúcida, conectada a una vena de mi brazo izquierdo.
Me dejaron solo con el extraño personaje. Mi esposa salió también de la habitación. Quería indagar, preguntar a los médicos; quería saber lo que me estaba ocurriendo. Nada bueno se imaginaba, y ello lo llevaba escrito en el rostro. Al volver al lado mío la noté más triste, más preocupada. Había terminado el trasiego de las primeras atenciones, las únicas que cabían, y llegaba el momento de la reflexión, de enfrentarse con la realidad, incluso con el futuro. Mi esposa puso su mano en mi frente y fue a sentarse, en silencio, al fondo de la habitación.

No era necesario que me dijera nada. Yo sabía que se me había roto el corazón y que aquella rotura era la que me producía el monstruoso dolor que me tenía inmovilizado en el lecho. Se me habían administrado calmantes, pero el dolor persistía. Sin embargo, transcurridas las dos primeras horas, ignorando yo que mi presión arterial estaba amenazadoramente por debajo de siete, cobré una súbita confianza -bien sabe Dios que injustificada- por varias cosas que fui valorando en torno a mi circunstancia y que me dieron la seguridad de que nada irreparable me iba a ocurrir. Respiraba bien: tenía a mi esposa allí, liberándome de la soledad experimentada momentos antes; el gotero, que acababa de señalar como «extraño personaje», palpitaba delante de mí, y en cada palpitación, de doce a quince por minuto, metía en mi sangre una gota de su sangre blanca y vivificadora; el rumor $\mathrm{M}$ sanatorio cobraba conciencia en mí, como también lo cobraba el ruido de la calle... El dolor no se me iba, pero ya no era él sólo quien ocupaba toda mi capacidad de retentiva, de atención, y hasta en ocasiones, aunque más bien fugaces, la voz de una enfermera, el paso de una camilla o el menor movimiento de mi esposa dominaban, sobre el dolor, todo el campo de mi conciencia, en ningún momento enajenada.

Me hubiera gustado explicar todo esto a mi esposa; sé que la hubiera tranquilizado. Pero yo sabía también que debía callar, que debía permanecer quieto y silencioso, sin hacer el menor esfuerzo. Sabía también que en aquellos momentos me lo estaba jugando todo. Y no me jugaba tan sólo lo mío, sino también una parte considerable de lo que debía a los míos, y hasta a mis amigos. No ignoraba lo que me 
sucedía. Ya, después del primer electrocardiograma, había preguntado al médico si se trataba de un infarto de miocardio; el médico me contestó, con piadosa intención tranquilizadora, que se trataba de algo perteneciente a la familia de los infartos. Con ese conocimiento, que eliminaba mi sospecha para convertirla en hecho cierto, me dispuse, con fe, con confiada decisión, a defender mi vida en todo aquello que de mí dependiera. Y lo que de mí dependía en aquellos instantes era la obediencia y la inmovilidad.

Ya de madrugada, después de cerca de veinte horas de la crisis, y como consecuencia de dos inyecciones, la segunda a las dos horas de la primera y casi anestésica, me calmó el dolor y ya no volvió a aparecer. Una gran paz me invadió. Respiraba acompasadamente. Mi esposa me pasó multitud de veces un pañuelo impregnado de agua de colonia por la frente y por el cuello.

-No siento ya dolor alguno -le dije.

-No hables. Todos sabemos que estás mejor.

-Acuéstate y descansa.

-No estoy cansada, ni tengo sueño. Estoy muy bien en este sillón. Ya me acostaré mañana. Podían ser las dos de la madrugada.

Reinaba en el sanatorio un silencio profundo. la noche que tanto asusta a los enfermos y a los ancianos, estaba allí presente, materializada en quietud. Yo procuraba escucharla. Intentaba descubrir la menor palpitación de ella, bien fuera el paso silente de la enfermera de vigilancia, o el leve quejido de algún hospitalizado, o el ruido de algún vehículo rodando lejano... No se oía nada. No debía haber enfermos graves en el sanatorio, aparte mi caso, claro está, de una gravedad extrema.

Hice regresar mi mente desde fuera del establecimiento a mi habitación, que permanecía en una sedante semipenumbra. Salía de la parte baja del muro que yo tenía a la izquierda, a un palmo escaso del rodapié, una luz escasa y ratiza. No se distinguía con nitidez el perfil de los objetos, pero de tenerse que mover entre ellos no hubieses tropezado con ninguno. Yo adivinaba el bulto de mi esposa dormitante en el sillón del fondo; la oía respirar tranquila y eso me hacía un gran bien.
Acabé escuchándome a mí mismo. Quería sentirme vivir, sin saber exactamente si mi deseo era, en mi circunstancia, bueno o malo. Siempre he pensado que son felices aquellos que no se sienten vivir, aquellos cuyas horas, cuyos días les resbalan por la piel sin apercibirse de ello. Al preso, o al enfermo, seres en verdad infelices, les ocurre lo contrario: las horas gravitan sobre ellos con pesadez de plomo; tanto pesan que cansan y envejecen. Pero yo pienso esto ahora, o lo pensé cien veces antes de que el corazón me traicionara. Durante mi noche primera en el sanatorio mi preocupación era más simple, aunque más dramática. Quería tan solo escuchar mi corazón, vigilar su marcha, espiar cada uno de sus latidos. No le oía en absoluto. Parecía no tener corazón. Sólo poniéndome la mano sobre el pecho percibía su hondo y tenue rumor. También podía buscar mi pulso, pero ya el médico, que en una ocasión me vio tomármelo, me aconsejó que no lo hiciera. «El pulso -me dijo- no sólo hay que oírlo; es preciso también interpretarlo». Había que obedecer y me quité de la cabeza la idea de llevar mis dedos a la muñeca. Yo debía atenerme a las instrucciones. Llamar. El médico de guardia estaba allí y sabía lo que tenía que hacer. Acabé pensando que la quietud de mi corazón debía ser un magnífico síntoma.

Fue entonces cuando, abandonada mi centinela de la noche y de mí mismo, volví a reparar en El Gotero, a quien, desde este momento, debo dar nombre propio. Continuaba yo unido a él. Su arteria hialina, como un cordón umbilical extracorpóreo, permanecía incrustada en la misma vena de mi brazo izquierdo. Yo tenía la viva impresión de que El Gotero, tan silencioso, tan firme a mi lado, tan erguido, batallaba por mi contra la muerte; me daba una sangre nueva, gota a gota, para continuar viviendo; calafateaba mi corazón herido, tenaz, incansable, sin daño ni molestia alguna para mí... Por primera vez, aunque ya antes lo había calificado de «extraño personaje», se me apareció El Gotero como un ser humano, con sensibilidad, con conciencia. Por eso mismo debo darle nombre propio. Por eso y porque, de noche, tenía verdaderamente forma humana. La lucecita ratiza le hacía brillar la cabeza, con un punto de luz más intenso en lo alto, digamos en la frente. Entonces, 
por unos momentos, se me antojaba un cíclope, gigante hijo del Cielo y de la Tierra, pero igualmente amigo.

La sombra de su cuerpo traslúcido se proyectaba contra la pared opuesta a la de la lucecita, formando extraña combinación de líneas y manchas claras y oscuras. Estampado contra el muro, El Gotero se deshumanizaba totalmente, después de adquirir proporciones monstruosas. Hubiera querido poder dibujar aquello que veía en la pared. ¿Qué era exactamente lo que veía? Nada en concreto. Lo mismo un caballo desbocado, que una mujer sobre una nube, que una batalla, que un cuerpo humano roto en pedazos, todo dependía del punto exacto donde fijase la mirada. La verdad es que aquella visión, digamos calidoscópica, me entretuvo mucho rato, pues yo me esforzaba, libre totalmente de sueño, de encontrar en la pared nuevas figuras y dibujos cada vez, nuevos monstruos, hasta moví un poco el brazo para que el movimiento de la goma diera cierta vida a las fantasmagorías del muro. Si era verdad que el tiempo trabajaba en favor mío, la manera de hacerlo transcurrir de aquel modo, cuando poco más cabía hacer por la noche, era una manera adicta, por no decir formidable.Volví la mirada a El Gotero. Volví a verle humano. Tan humano que me pareció que se disponía a hablarme. Yo sí que le hubiera hablado, y en alta voz. Pero no podía ni debía hacerlo.Me hubieran tomado por loco.Al menos, se habrían interpretado mis palabras como el delirio de un moribundo. Permanecí mudo, pero mi silencio y el de mi amigo y aliado El Gotero me llevó a cierto diálogo de mente a mente, de la suya a la mía, sólo audible para él y para mí. De aquel diálogo con El Gotero me acuerdo con frecuencia, y hasta quiero alguna vez reconocer la voz amiga de aquella noche de prueba que, Dios sabe por qué, me resultó más adicta de lo que era presumible esperar. He aquí el diálogo:

- ¿Qué piensas de mí? -me dijo.

-Pienso que eres mi amigo y que me estás ayudando a salir del peligroso trance en que me veo.

-Piensas bien. No te hago daño, ¿verdad?

-Ningún daño.

-Lo sé. Pero también sé que soy un poco molesto.
Ahora, tú y yo, y por algún tiempo, somos como dos hermanos siameses, unidos por una arteria vital. Más vital para ti que para mí.

-Lo sé también. Sé que me estás dando algo, digamos como una sangre blanca, aunque no sé exactamente qué.

-Yo soy amigo de la «Triaca máxima» de los antigüos.

-¿Cómo dices? ¿La «Triaca máxima»?

-Sí, eso digo. ¿Sabes tú lo que es la «Triaca máxima»?

-Pues sí que lo sé, y no me gusta que tú seas eso. No te rías.

-Me río porque me resultas algo más cobardón de lo que te había supuesto. Te he visto muy tranquilo durante todo el día y lo que va de la noche. Ahora te sobresaltas más de lo debido con sólo haberte nombrado lo de la «Triaca máxima». Ya sé por qué. Sé lo que piensas. Pero voy a tranquilizarte. Lo de «triaca» viene por la cantidad de cosas que llevo en el cuerpo y que te voy suministrando gota a gota; pero esta «triaca» mía es una «triaca» consciente, no como aquella otra de los antiguos que era una «triaca» ciega. Todo lo que yo te doy lo necesitas: las vitaminas, las prednisonas, la heparina, incluso la insulina, por si las moscas... Estoy nutriendo y reparando, con el mejor cemento que tengo, la grieta que se te ha abierto en tu miocardio. Lo importante es que la dejemos tierna y casi invisible. Y eso depende mucho de ti, de tu fe, de tu reposo, de tu inmovilidad. Tú déjame hacer a mí. ¿De acuerdo? Yo vengo de México, ¿sabes? Algo devuelve a España su hija predilecta. Vengo en forma de «triaca», la palabreja que te ha asustado; quizá debiera haber empleado el vocablo «cóctel», porque la verdad es que yo soy como un «cóctel», es decir, soy un «cóctel» auténtico. Un «cóctel» inventado por un gran «Perico Chicote» de la medicina mexicana llamado Sodi Pállarés. Un «cóctel» que ya comienza a servirse en España, traído por hombres de buen paladar científico, por hombres de mucho estudio y de gran fe. ¿Te hubiera gustado más oírme hablar de «cóctel» en vez de «triaca»? Di, contesta.

-¿Qué? No te he oído bien. 
-Ya veo que te estás durmiendo. Será mejor eso, que descanses un rato. Nos sobrará tiempo para hablar. Ahora duerme. Confía en mí. Yo estaré vigilando. A mí no me vence jamás el sueño.

Concilié el sueño sobre las cuatro de la madrugada y dormí hasta las ocho. Los que vigilaban mi sueño dijeron que éste era reposado, tranquilo. Habían transcurrido veinticuatro horas desde la crisis y el optimismo, todavía demasiado tierno, comenzaba a brotar.

El Gotero se había quedado exangüe. Yo, como una sanguijuela insaciable, le había sorbido toda su sangre. Dos enfermeras, una rubita muy mona y otra morena muy airosa y decidida, desmontaron en un santiamén El Gotero. Con sólo dar media vuelta a una clavija, El Gotero se engulló a sí mismo, penetrando la parte alta y más fina de su cuerpo en la más baja y gruesa. La cabeza le fue materialmente arrancada. Me dolió aquella derrota de mi amigo. Lo desconectaron también de mí, dejando libre mi brazo izquierdo, que me dolía todo, pesado y torpe. Lo había mantenido inmóvil muy cerca de un día entero y demasiada razón tenía de quejarse un poco.

-Mueva el brazo, sin violencia, pero muévalo un poco -me dijo la enfermera morena-. Vamos a ponerle El Gotero en el brazo derecho.

Me alegré. El Gotero me inspiraba una gran fe, una enorme confianza. No sé por qué, no sabría explicarlo, me hice a la idea de que mientras tuviese El Gotero puesto nada malo me podía ocurrir. Con él, éramos dos a luchar por una misma causa, en este caso la mía. El Gotero era para mí el mejor centinela que podría encontrar, un soldado que rebosaba energía, vitalidad, dispuesto a batirse por mí hasta el final. Un soldado que no me abandonaría hasta considerar ganada la batalla.

Si momentos antes, y escasos segundos, El Gotero fue demontado y reducido a algo informe y sin sentido, ahora, de nuevo, saliendo de su retordido enanismo volvía a cobrar estatura gallardía; volvía a tener la cabeza en su sitio, brillante y altiva. El practicante, con pericia, me buscó la vena precisa en el brazo derecho y me conectó con El Gotero, bien sujeta la conexión en mí con tiras de esparadrapo.
El médico vino unos instantes después. Me midió la presión arterial:

-Once -dijo-. Esto va bien. Allá, sobre mediodía, sacaremos un poco de sangre y haremos un nuevo análisis.

Mi esposa preguntó sobre mi alimentación. Hasta nueva orden, tomaría alimento líquido, o casi líquido, sin incorporarme demasiado en la cama: leche, sopa, purés, naranjada, y así por el estilo.

Nos quedamos solos mi esposa y yo. Teníamos alguna cosa que decirnos. Poco podía hablar yo, pero en voz baja, casi susurrando, algo podía decir.

-¿Cómo te encuentras? -me dijo con su mano suave e ingrávida sobre mi frente.

-Me encuentro muy bien. Creo que saldré de ésta.

-¿Quieres que 1lamemos a Miguel?

-No. Está preparando su segundo examen parcial y no debemos trastornarlo. La verdad es que no me va a ocurrir nada. Ten fe. ¿Y el pequeño? Tráemelo.

-El pequeño está muy bien, con nuestros vecinos. Está contento y tranquilo. Le hemos dicho que estamos en Murcia porque la tía se ha puesto enferma. Mañana o pasado te lo traeré... Tú debes permanecer ahora tranquilo, sin experimentar ninguna clase de emociones.

-He dejado algunas cosas pendientes. Son intereses.

-Déjate estar de intereses. El único interés está en ti. Todo lo demás puede esperar.

-Has de ocuparte de mi baja en el trabajo.

-Me ocuparé. Hala. Ya hemos hablado bastante.

Me dio un beso en la frente y salió un momento de la habitación. Yo cerré los ojos y me puse a escuchar la palpitación del sanatorio y de la ciudad. Mi corazón permanecía como dormido. No lo sentía en absoluto. Su silencio me agradaba; su persistente quietud me decía que la cosa debía ir bien. Otra cosa bien distinta -pensaba yo- debería ocurrir si la emprendiera a saltos, o a carreras desbocadas, o a cualesquiera arritmias. Tenía motivos para estar confiado, y uno de ellos, quizá el de más valor, era la cara de mi esposa, que había perdido bastante de su miedo del día anterior, y también el corto diálogo 


\section{2 - Cultura de los Cuidados}

que acabábamos de tener. Pienso ahora que era excesiva mi confianza y que el enfermo, con conmovedora ingenuidad, no hace otra cosa que buscar motivos que le lleven por el camino, tantas veces engañoso, de su curación.

La segunda noche de mi estancia en el sanatorio tuve con $\mathrm{El}$ Gotero una conversación importante. Al menos, a mí me pareció que fue importante, y me lo continúa pareciendo ahora, a los dos meses y medio de la crisis, no totalmente abandonado aún mi tiempo de reposo.

No me resisto a trasladar aquí, con la fidelidad máxima, lo que El Gotero y yo hablamos la noche aquella.

-¿Estás asustado? -comenzó diciéndome.

-Pues... no, aunque tú pienses lo contrario.

-Yo no pienso nada. He visto a otros muy asustados. Tú, la verdad, no debes haberte asustado mucho. No te has conducido como otros, pidiendo a la desesperada un sacerdote.

-Yo no creo que pedir un sacerdote en una situación como la mía sea algo que determina el miedo, sino otra cosa, la fe, las creencias... No he llegado a plantearme el problema de la eternidad. Más que al sacerdote, busqué al hombre de ciencia, al médico, y el médico fue quien te trajo a ti, y tú eres quien me inspiras confianza.

-Pero... ¿no has pensado en la muerte?

-Sí, claro. He pensado en la muerte. En la muerte piensa todo el mundo. Quizá piensan menos en ella los que la ven de cerca; en esta circunstancia de la cercanía de la muerte, más que pensar en ella se piensa en combatirla. Creo que en esto ocurre lo que le ocurre al soldado antes de la batalla. Piensa y teme las vicisitudes, los peligros de la batalla; pero ya metido en ella, es la lucha lo que le absorbe, su defensa, la defensa $\mathrm{M}$ terreno que se le ha confiado...

-¿No te asusta la muerte?

-A todo el mundo le asusta la muerte. A unos más y a otros menos. Pero contra el miedo a morir hay ciertas defensas. Una de ellas, y de las más importantes, es la desaparición de los seres queridos. La muerte de ellos nos libera bastante del miedo a morir. Puedo asegurarte que la muerte no me espanta demasiado. Vi morir mucha gente en mi juventud.
Muchos hombres afrontan la muerte con entereza. No dejo de reconocer que la muerte es el gran problema de cada uno, un problema, si quieres tremendo, que cada uno ha de resolverse solo, sin ayuda de nadie. Quizá es éste el aspecto más dramático de la muerte. Cuando la muerte nos llama, lo hace a cada uno de nosotros por separado. La muerte es un asunto personal, particularísimo. Pero, bien pensadas las cosas, el problema de la muerte es más problema para los que se quedan que para los que se van. Los que se quedan son los que continúan pensando en ella, los que se atormentan en razón directa a su miedo.

-Me decías antes que no te has planteado el problema de la eternidad. Eso quiere decir que no has pensado dónde quieres pasar la eternidad. ¿Has pensado dónde puedes pasar la eternidad?

-No. Ese pensamiento, como el bucear en la inmensidad del espacio pone vértigos en la cabeza, marea. Uno no debe martirizarse asomándose a esos abismos sin fondo. La eternidad... La infinitud... El vacío inacabable...

-En el fondo de todo eso está Dios.

-Dios está en mi conciencia. Dios es mi conciencia. Y mi conciencia es la voz que me dice si lo que hago es justo o injusto, si es honrado o no.

$-i$ Crees eso, que Dios es tu conciencia?

-Sí lo creo. La suma de todas las conciencias humanas, las pasadas, las presentes y las futuras es el Dios único y total.

-Es una manera de pensar muy peregrina.

-Aún te diré que muchos hombres logran asesinar su conciencia, es decir, logran asesinar, dentro de ellos mismos, a Dios, y entonces viven sin escrúpulos, a sus anchas, desvalijando al prójimo, prostituyendo a las mujeres, ciscándose con la justicia, con el honor. No tener conciencia es tener luz verde para perpetrar toda suerte de ignominias. Gentes de estas que han logrado asesinar su conciencia, que han logrado asesinar a Dios, hay suficientes para constituir ejércitos numerosos. A estas gentes es a las que habría que preguntar por la eternidad. Habría que decirles que el camino hacia Dios parte de la propia conciencia.

-Existe una especie todavía peor, querido amigo. Existe una familia de asesinos de su conciencia mu- 
cho más refinada que la otra, que la que persigue por el camino que sea la acumulación y disfrute de bienes materiales. Me refiero a los que, más que asesinar a su propia conciencia, más que asesinar a Dios, lo han sustituido por ellos mismos, por lo que llaman su estrella, su destino: son los soberbios o los que dejaron tras de ellos siembras horribles de cadáveres.

- ¿Alejandro, Atila, Napoleón, Hitler .. ?

-Esos y muchos otros más. No me tires de la lengua, pues tendría que dar el nombre de algún ideólogo, de algún cetro y hasta de alguna mitra.

$\mathrm{El}$ Gotero estaba nervioso. Era evidente que nuestra conversación lo había excitado. lo miraba yo fijamente. Como a medio metro de su cabeza tenía él el lóbulo transparente del pulso. La lucecita lo iluminaba muy bien y yo distinguía perfectamente cada gota que se desprendía al interior del lóbulo. Se producía cada vez como un estremecimiento de luz, muy tenue, pero estremecimiento al fin. Me di cuenta de que El Gotero había alterado mucho su pulso e hice sonar el pulsador, el vibrador de la habitación. Mi esposa se levantó sobresaltada y la enfermera apareció al momento las tranquilicé. No se trataba de mí, sino de El Gotero, que también, cuando se le ocurría, daba un rato de lata. Ahora bien, era dócil y se dejaba regular fácilmente. A los pocos momentos volvía a dar sus quince latidos por minuto, es decir, sus quince gotas vitales.

La conversación con El Gotero se había roto. Y además, la enfermera, al mover una silla que había adosada al muro de la lucecita, mató sus reflejos con el asiento y El Gotero se quedó a oscuras. No dije nada y me dispuse a dormir.

Al cuarto día de mi hospitalización me trajeron al pequeño, con sus cuatro años recién cumplidos. Entró en la habitación muy despacio, la cara asombrada, confundido por la mentira que se le había dicho.

Antes de decidirse a darme un beso, dijo:

-No estáis en Murcia. Me habéis engañado.

-Lo hicimos para no asustarte. Hala, dale un beso a papá.

El niño me besó y luego se enfrentó con $\mathrm{El} \mathrm{Go-}$ tero. Lo miró de pies a cabeza. Sobre todo, se fijó en la goma que iba de la ampolla a mi brazo. Luego puso sus ojos en mí, fíjamente:
-¿Qué es eso, papá?

-Es un aparato que cura.

$-i$ Duele?

-No duele nada. Ya ves que no me quejo. Ese aparato está curando a papá.

A partir de ese momento, el chiquillo comenzó a encontrarse en la habitación del sanatorio como en su casa. Fue problema tenerlo que sacar de ella para devolverlo a casa de nuestros vecinos.

No volví a conversar con El gotero hasta la noche anterior a mi despedida de él. Durante el día no podía hacerlo. Tenía siempre alguna visita de familiares o de amigos entrañables, que se pasaban horas enteras haciéndome compañía y hablando entre ellos. Por las noches, comencé a quedarme dormido sobre las diez, después casi de la cena, y El Gotero, sin protesta, permanecía a mi lado, mudo y eficiente, dándome la energía que a él le sobraba, dándome la vida.

Al séptimo día de la crisis, y después de un nuevo electrocardiograma, dijo el cardiólogo:

-Bien. Ha empezado la cicatrización. Todo ha ido mejor de lo que esperábamos. Enhorabuena. Creo que ha pasado el peligro. Pero hemos de continuar con el reposo absoluto. Mañana quitaremos ya El Gotero y comenzaremos con una medicación por vía oral.

Mi amigo El Gotero debió escuchar atentamente las palabras del médico. Y aguardó la llegada de la noche, la llegada $\mathrm{M}$ silencio, para cruzar unas postreras palabras conmigo. Yo, aquella noche, no sentía sueño alguno. Me dolía en el fondo tener que separarme de mi amigo. Pensaba que, en adelante, no podría apoyarme más en él y que todo debería confiarlo a mis propias fuerzas. Esta manera mía de pensar me infundía cierto temor. Yo vivía confiado con la ayuda de El Gotero; sin él, presentía yo cierta desvalida orfandad. Al menos, era evidente que mientras El Gotero estuvo unido a mí, mientras me estuvo suministrando su sangre blanca y mágica, nada malo me había acaecido; ahora, sin su apoyo, estaba por ver lo que pudiera ocurrirme. Esa nueva frontera de mi soledad en el esfuerzo, la verdad, me inquietaba un poco. La medicación, por buena que fuese, no podía sustituir la presencia física, humana, de El Go- 


\section{4 - Cultura de los Cuidados}

tero. Eso pensaba yo, en que unas píldoras y unas gotas para ser tragadas no podían reemplazar la abnegada centinela de El Gotero.

- Ya has oído lo que esta tarde ha dicho el doctor -me dijo la última noche-. Mañana por la mañana nos separaremos. Y cree de verdad que lo voy a sentir. Aunque me has tenido abandonado alguna noche, puedo decirte que lo he pasado bien contigo. Hemos hablado de cosas interesantes. No es muy corriente. ¿Qué me dices?

-Yo también sentiré separarme de ti. Me acordaré mucho tiempo de ti, de la compañía que me has hecho, de la ayuda que me has prestado. Ya sabes que le dije a mi mujer que te dibujara, y yo te prometo que hablaré de ti, con el elogio que mereces.

-No es necesario que lo hagas. No vale la pena. No soy tan importante. En vez de pensar en eso que piensas, podríamos hablar de cualquier cosa. Nos queda poco tiempo de estar juntos y debemos aprovechar el tiempo. Además, es posible que nos separen esta madrugada mismo. Ya ves que me estoy agotando.

-La inminencia de nuestra separación me dispersa el pensamiento y no encuentro tema de que hablarte. Porque no es cuestión de volver a aquello tan tremebundo de la eternidad.

El Gotero sonrió, y dijo:

-Mejor será, pues, que me escuches. Hablaré yo por los dos. Algo creo que puedo hacer por ti, y por otros muchos hombres, sin estar presente. Puedo darte unos consejos.

-Te escucho, amigo mío, y te agradezco el nuevo esfuerzo que quieres hacer por mí.

-Yo sé por qué has llegado tú a esta situación de peligro; sé por qué te has jugado la vida y has estado a punto de perderla: por la prisa, por el vértigo, por la ansiedad que últimamente has impuesto a tu vida. No me refiero al trabajo físico, sino a la sobrecarga emocional, a la falta de sosiego, al exceso de excitación nerviosa. El hombre se está deshumanizando y convirtiendo en máquina. Ya convertido en máquina, tantas veces bloqueada por otras máquinas humanas, corre con aterradora frecuencia hacia la meta del infarto de miocardio y de otros trastornos circulatorios. Es necesario, amigo mío, regresar a la personalización, a la humanización. Nadie podrá saltar, por mucho que se empeñe, más allá de su sombra. Piensa en tu corazón y piensa en serio. Debe ser de buena calidad, de lo contrario, ni yo estaría hablándote ahora ni tú escuchándome. Piensa, amigo mío, que el corazón es un pequeño y delicado motor que no soporta sin protesta ritmos demasiados acelerados, ansiedades demasiado angustiosas... Sosiega tu ánimo, amigo mío, y da tiempo al tiempo. Camina sin prisa y podrás hacerlo sin pausa, pero huye de todo paroxismo, de todo exceso. Vete a casa, al lado de tu esposa y de tus hijos, y trabaja a compás, a «tempo lento», que no es flojo trabajar, sea dicho de paso. Lo demás, todo lo demás, el comer mucho, el beber mucho, el sobrecargar tus músculos o tus nervios es puro embrutecimiento, es caminar hacia el infarto de miocardio, hacia la muerte antes de tiempo. Y..., nada más. Todo eso quería decirte. Lamento no poder seguir. Yo también me fatigo, sobre todo si, como ahora, veo que me quedo vacío. Perdona, amigo. He de despedirme de ti. Mucho he intimado contigo, pero no me gustaría volver a verte por aquí. De ti depende, sólo de ti... Buenas noches. Hasta... nunca.

El Gotero pareció apagarse. Quizá yo me moví para adoptar una posición más cómoda y perdí la poca luz que se desprendía de la cabeza de mi amigo. Me había impresionado su parlamento. Estuve meditando largo rato sobre lo que me había dicho El Gotero. Trataba de encontrar dónde y cuándo había cometido yo excesos. No lograba averiguarlo. Pensé que todas las personas no son iguales y que la acumulación, en ellas, de las cargas emocionales, no es la misma aunque concurran las mismas circunstancias. De todos modos, había que reconsiderar el paso y el ritmo. Había que pararse en seco, y comenzar luego otra vez a caminar, después de elegido el camino y acordado la marcha conveniente, reñida, desde luego, con toda presura, con toda aceleración, de acuerdo con el propio motor vital, uno e insustituible.

Me vencía ya el sueño, pero, no sé por qué, me vino a la memoria la recomendación de Felipe II a su fiel secretario Benavides:

-Holgáos en vuestras tierras de Ávila, querido Benavides. Es tiempo.

Debí dormirme en seguida. 